\title{
Ferdinand de Saussure: relações possíveis entre a língua e a história
}

DOI: http://dx.doi.org/10.21165/el.v49i1.2496

\section{Stefania Montes Henriques ${ }^{1}$ \\ Micaela Pafume Coelho²}

\section{Resumo}

Neste trabalho, partimos da análise de alguns documentos de Ferdinand de Saussure para propor relações possíveis entre a língua e a história. A busca por estabelecer essas relações se justifica na medida em que, constantemente, o conceito saussuriano de língua é tomado como um elemento isolado dos fenômenos sociais, sendo entendido como um objeto de estudo que se constitui unicamente a partir de uma abstração. Considerando isso, hipotetizamos que essas críticas se estabelecem, pois desconsideram que, para Saussure, além de ser um sistema de signos, a língua é, também, uma instituição social, que apresenta uma relação necessária com os fenômenos sociais que constituem a história. A partir dessa hipótese, mostramos que tanto a história da língua, como a história dos povos se mostram relevantes para a conceituação de língua apresentada nos documentos de Saussure fontes de nosso trabalho.

Palavras-chave: Ferdinand de Saussure; língua; história; Niebelungen.

1 Universidade do Estado de Minas Gerais (UEMG), Passos, Minas Gerais, Brasil; temontess@gmail.com; https://orcid.org/0000-0002-4517-0121.

2 Instituto Federal de Educação Ciência e Tecnologia de Mato Grosso (IFECT), Alta Floresta, Mato Grosso, Brasil; micaelapafumecoelho@gmail.com; https://orcid.org/0000-0001-7734-7633. 


\title{
Ferdinand de Saussure: possible relations between language and history
}

\begin{abstract}
In this work, we start from the analysis of some documents by Ferdinand de Saussure to propose possible relations between language and history. The search to establish these relations is justified since the Saussurian concept of language is constantly taken as an element isolated from social phenomena, being understood as an object of study that is solely constituted from an abstraction. Considering this, we assume that these criticisms are established because they disregard that, for Saussure, besides being a system of signs, language is also a social institution, which presents a necessary relationship with social phenomena. From this hypothesis, we show that both the history of the language and the history of people are indeed relevant to the conceptualization of language presented in Saussure's documents used as sources of our work.
\end{abstract}

Keywords: Ferdinand de Saussure; language; history; Niebelungen.

\section{Introdução}

A publicação do Curso de linguística Geral (CLG), em 1916, foi responsável por levar a público a teorização de Ferdinand de Saussure que apresenta a delimitação da língua enquanto objeto de estudo da Linguística, outorgando a essa disciplina seu lugar entre as ciências modernas. A definição desse objeto, contudo, não se dá de maneira ordenada e linear (SILVEIRA, 2007); ao longo da edição do CLG, é possível encontrar definições de língua que se complementam ou até mesmo caminham em trajetórias que parecem, em um primeiro momento, antagônicas. Nesse sentido, a partir do CLG, podemos considerála como uma instituição social, ou seja, como fruto de um acordo tácito entre os membros de uma comunidade, e também podemos compreendê-la como um sistema de signos que se estabelecem por meio de relações arbitrárias, cujo funcionamento é independente dos aspectos sociais.

Apesar de haver, desse modo, duas definições possíveis de língua - uma que abarca o aspecto social e outra o funcionamento do sistema -, a recepção da edição no decorrer do século XX nos leva a observar que a compreensão de língua consagrada por seu conteúdo está relacionada, principalmente, à língua enquanto sistema. Obviamente, isso ocorre tendo em vista que tomar a língua enquanto sistema é o que permite a Saussure efetuar os deslocamentos necessários para a fundação da Linguística Moderna, ou seja, é o que lhe proporciona, na perspectiva da recepção do CLG, o estatuto de fundador de uma ciência. 
Justifica-se, assim, que principalmente - ou somente - o sistema tenha sido considerado pelas leituras realizadas no século XX e, consequentemente, que as críticas direcionadas às elaborações saussurianas tenham incidido justamente nesse aspecto. Dentre os estudiosos que fazem essas críticas, podemos citar Volochinov (1929), Meillet (1958), Labov (1976) e Chomsky (1965), dos quais as teorias reivindicam, muitas vezes, o lugar dos elementos que compõem as chamadas "exclusões saussurianas": a fala, a história, o referente e o sujeito.

Na contramão desses autores e considerando o quadro epistemológico em que Saussure se encontra no início do século XX, pensamos que suas elaborações abarcam esses elementos não só nos cursos de linguística geral, como também em seus manuscritos, justamente porque há outra definição de língua, além daquela que prioriza o funcionamento do sistema. Considerar a língua enquanto instituição social permite colocar em confluência o seu funcionamento sistêmico e os aspectos que lhe são exteriores e que, supostamente, teriam sido excluídos. É seguindo essa perspectiva que, neste artigo, propomos uma reflexão acerca da relação entre língua e história - uma das exclusões saussurianas - com objetivo de evidenciar que, além de haver uma concepção de história subjacente ao sistema, essa relação permite pensar, nas elaborações saussurianas, os aspectos sociais de uma comunidade falante.

Para que isso seja feito, estabeleceremos um percurso por alguns documentos saussurianos ${ }^{3}$ : i) o manuscrito referente à Primeira Conferência, proferida pelo linguista na Universidade de Genebra em 1891; ii) o CLG, bem como os cadernos de alguns dos alunos que estiveram presentes em seus cursos de Linguística Geral, ministrados entre 1907 e 1911 na Universidade de Genebra; iii) o caderno Niebelungen, pertencente ao arquivo Ms. Fr. 3958, em que estão agrupados os manuscritos saussurianos sobre as lendas germânicas, escritos entre 1903 e 19104.

Antes de iniciarmos nossa explicitação, entretanto, é necessário nos posicionar acerca da relação entre o CLG e os manuscritos de Saussure. Testenoire (2019), ao tratar

3 Os manuscritos investigados neste artigo foram adquiridos por meio do Grupo de Pesquisa Ferdinand de Saussure (GPFdS/CNPq) junto à Bibliothèque de Genève (BGE). Os critérios de transcrição dos manuscritos utilizados foram os seguintes: tachado indica rasura; sublinhado indica que Saussure sublinhou as partes do texto; sobrescrito indica incisos acrescentados pelo autor. Os negritos que porventura vierem a aparecer nas citações são das autoras e indicam o destaque para determinadas partes da citação.

$4 \mathrm{~A}$ escolha pelos manuscritos referentes ao Niebelungen justifica-se por dois motivos principais: 0 primeiro deles concerne ao fato de que, apesar do estudo saussuriano sobre as lendas germânicas contemplar outras narrativas - como a de Tristão - as considerações sobre o Niebelungen é mais extensa do que as outras. Em segundo lugar, essa narrativa é citada por Saussure em outros momentos de sua pesquisa, como nas comunicações proferidas à Societé d'Histoire et Archéologie de Genève, entre 1901 e 1904. 
das aproximações possíveis entre o CLG e os anagramas, aponta três caminhos para considerar as relações entre esses documentos: a tese da ignorância mútua das duas pesquisas, a de sua oposição e a de sua complementaridade. A nosso ver, essas possibilidades podem ser estendidas às relações possíveis de serem estabelecidas tanto entre o CLG e os outros manuscritos saussurianos (para além dos anagramas), como também entre a teorização de Saussure sobre Linguística Geral e suas reflexões sobre os demais temas de interesse do linguista.

Tendo isso em mente, em nosso trabalho nos posicionamos de modo a tomar os diferentes materiais de Saussure e suas diversas áreas de interesse como complementares. Isso porque, para nós, sua teorização acerca da Linguística Geral - exponenciada por meio do CLG - bem como os manuscritos que apresentam suas reflexões sobre as lendas germânicas têm um ponto principal em comum: todos eles tratam, de alguma forma, sobre a língua e suas confluências com as exclusões saussurianas.

\section{A história na Primeira Conferência}

Apesar de a Primeira Conferência consistir na primeira lição ministrada por Saussure em seu curso Phonétique du grec et du latin, que ocorreu na Universidade de Genebra em 1891 (CHIDICHIMO, 2009) - ou seja, um tema de natureza comparatista - notamos que, nesse documento, há uma busca por reflexões acerca da natureza da língua. Nessa busca, o linguista estabelece uma distinção entre a história da língua e a história dos povos, a qual pode ser observada no seguinte momento do conjunto de manuscritos supracitado:

É-A presença de idiomas célticos na Gália, e seu desaparecimento lento sob influência da dominação romana é constituída p. ex. de grandes fatos históricos. É o ponto de vista da língua na História, mas não é o ponto de vista da história da língua. (SAUSSURE, $1^{\text {a }}$ C., 1891, f. 16, grifo em negrito nosso, tradução nossa) ${ }^{5}$.

Embora essa distinção tenha sido metodologicamente necessária para que Saussure conseguisse delimitar a Linguística como uma ciência autônoma, que independa de outras disciplinas para que exista, questionamos se é, de fato, possível estabelecer uma distinção categórica entre as perspectivas da história da língua e da língua na história. Questionamos isso, pois, se a língua é histórica, ela também se estabelece ao longo do tempo, e o acesso a ela se dá, portanto, por meio da história dos povos. Por outro lado, o registro da história dos povos só é possível de ser feito por meio da língua falada e de sua representação pela escrita.

5 No original: " C'est La présence d'idiomes celtiques em Gaule, et leur disparition lente sous l'influence de la domination romaine est constituent pr. ex. De grands faits historiques. C'est le point de vue de la langue dans l'Histoire, mais ce n'est pas le point de vue de l'histoire de la lgue. ». 
Isso faz com que a análise da(s) língua(s) dependa, de alguma forma, da compreensão dos aspectos culturais desses povos, pois não há como conhecer uma história sem entender minimamente os contextos - geral e particular - que levaram aos fatos que a compõem. Por conseguinte, não há como conhecer um povo sem conhecer a sua língua e, em contrapartida, não há como conhecer e analisar uma língua sem conhecer seu povo e sua cultura. A respeito dessa relação, Saussure ( $1^{\text {a }}$ C., 1891, f. 15, grifo em negrito nosso, tradução nossa) ${ }^{6}$ ressalta:

É sobre esse assunto que eu gostaria de solicitar sua atenção, quase sem outro preâmbulo, porque ele contém tudo: quanto mais estudamos a língua, mais chegamos a methor nos penetrar ainda no fato de que tudo na língua é história, isto é, que ela é um objeto de eonsi-de análise =deração histórica, e não de eonsideração de análise abstrata, que ela se compõe de fatos, e não de leis, que tudo que parece orgânico na linguagem é, em realidade, contingente e completamente acidental.

Relacionada à história, a língua é mais facilmente compreendida como um objeto de natureza concreta, o que a afasta de uma concepção que a considere unicamente como uma abstração - ou, dito de outro modo, como um objeto estritamente formal. Dessa forma, a língua é concreta porque é composta de fatos, ou seja, de acontecimentos que existem independentemente da intervenção do experimentador. Embora o linguista pareça se referir aos fatos linguísticos, consideramos que esses fatos estão necessariamente vinculados aos fatos que compõem a história dos povos. Uma mudança linguística (que é um fato de língua), por exemplo, ocorre tanto porque o sistema da língua permite, como também porque a comunidade falante a propõe, seja devido a questões políticas (como é o caso dos estrangeirismos) seja devido a outras questões de cunho social.

Considerando esse mesmo trecho da P.C., é igualmente possível que façamos uma aproximação entre a qualidade da língua de ser concreta e sua qualidade de ser empírica, uma vez que ambas estão relacionadas aos fatos, aos dados e são independentes de uma formulação teórica. Além disso, é importante rememorar que, nesse momento de sua teorização, Saussure considera a língua como as manifestações diversas, em complementaridade com a linguagem, que está relacionada aos princípios gerais. Essa consideração também corrobora com a caracterização da língua como objeto empírico, concreto, deixando, por consequência, à linguagem o estatuto de objeto matematizado, neste momento das elaborações do linguista.

6 No original : "C'est sur ce sujet que j'aurais voulu solliciter votre attention presque ss autre préambule, car il contient tout : plus on étudie la langue, plus on arrive à mieux se pénétrer encore de ce fait que tout dans la langue est histoire, c.à.d. qu'elle est un objet de eonsi=dération danalyse historique, et non de eonsidération d'analyse abstraite, qu'elle se compose de faits, et non de lois, que tt ce qui semble organique ds le langage est en réalité contingent et complètement accidentel. ». 
A esse respeito, sublinhamos que, também para Saussure, pensar em história significa pensar justamente na cultura e nos fenômenos sociais. Isso parece ser evidenciado pelo inciso que aparece no trecho a seguir, logo após a palavra "história" na quarta linha:

Qual é, portanto, a $2^{\mathrm{a}}$ condição frisada implicada pela palavra ciência histórica - é

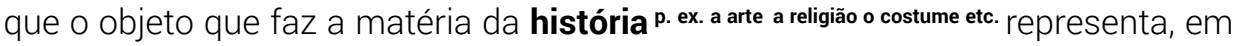
um certo sentido, atos humanos, regidos pela vontade e inteligência humana, - e que, além disso, devem ser tais que eles não interessam somente ao indivíduo, mas a uma à coletividade. mportante. (SAUSSURE, $1^{\text {a }}$ C., 1891, f. 18, grifo em negrito nosso, tradução nossa) ${ }^{7}$.

A história é composta, de acordo com Saussure, por atos humanos, como a arte, a religião, os costumes etc. Do ponto de vista de Durkheim ${ }^{8}$, esses atos humanos são fatos sociais, pois consistem em instituições e comportamentos dos indivíduos que foram definidos socialmente e passados por meio da educação. Logo, se partirmos das elaborações desse filósofo, temos que a relação da língua com a história outorga à primeira não apenas a qualidade de ser concreta, mas também a qualidade de ser social.

Porém, essa não é a única perspectiva do objeto da Linguística que Saussure procura destacar. Junto a ela, o linguista ressalta também a possibilidade de se considerar a língua como um sistema que pode ser compreendido independentemente desses fenômenos da sociedade, muito embora eles estejam intimamente vinculados às línguas, entendidas como as manifestações linguísticas dos povos. Concernente a isso, destacamos o seguinte trecho da P.C.:

Mas todos esses fatos, grandes ou pequenos, devido aos quais a língua se encontra misturada ( ${ }^{*}$-de perto) à vida dos povos, do fato tomado à vida politica social, literária não são, eu o repito, ou são apenas de vez em quando o que podemos chamar a vida da língua ela mesma. (SAUSSURE, $1^{\text {a }}$ C., 1891, f. 16-17, grifos em negrito nossos, tradução nossa) ${ }^{9}$.

7 No original : "Quelle est donc la 2 ème condition frisée impliquée par le mot de science historiq. - c'est que l'objet qui fait la matière de l'histoire p. ex. lart la religion le costume etc. représente, ds un sens quelconque, des actes humains, régis par la volonté et l'intelligence humaine, - et qui d'ailleurs doivent être tels qu'ils n'intéressent pas seulement l'individu mais une ${ }^{\text {la }}$ collectivité. Importante ».

8 De acordo com Durkheim (2011 [1893], p. 11-12), a língua, tal como a religião, a cultura e outros aspectos, existe independentemente dos indivíduos tomados isoladamente, ou seja, esses são aspectos que "existem fora deles [dos indivíduos]. O sistema de signos de que me sirvo para expressar meu pensamento, o sistema monetário que emprego para pagar minhas dívidas, os instrumentos de crédito que utilizo em minhas relações comerciais, as práticas adotadas em minha profissão etc. funcionam independentemente do uso que faço deles.".

9 No original: «Mais tous ces faits, grands ou petits, par où la langue se trouve mêlée (et* de près) à la vie des peuples, de le fait pris àla vie politiq. sociale, litter., ne sont pas je le répète ou ne sont que de temps à autre ce qu'on peut appeler la vie de la langue elle-même. ». 
Neste momento, torna-se notável que a separação, proposta por Saussure, entre história da língua e história dos povos não parece se sustentar de forma tão categórica. Isso porque, como é possível observar, o linguista mesmo afirma que os fatos que fazem com que a língua se encontre misturada à vida dos povos interferem na língua de vez em quando. Ora, se houvesse uma separação estrita entre os dois tipos de história propostos pelo linguista, muito provavelmente não haveria uma interferência tão significativa ao ponto de levar o linguista a considerá-la em sua teorização. Assim, entendemos que o uso da expressão "apenas de vez em quando" é um modalizador da distinção entre história da língua e história dos povos, e denuncia um titubeio do linguista com relação à separação que ele propõe.

Por mais que Saussure busque mostrar que é possível considerar um dos "dois lados da moeda" de forma independente do outro, o entrelaçamento que há entre o sistema e o fato linguístico é tão íntimo que, vez ou outra, Saussure se mostra preso em sua própria argumentação. É o que o ocorre no trecho a seguir:

É por outro ponto de vista, por conseguinte, que a ciência da linguagem reivindica o título de ciência histórica. É que toda língua tem uma história, nela mesma tem uma história que se desenrola perpe==tuamente, que é feita de uma sucessão de acontecimentos linguísticos, exemplo que os quais não tiveram qualquer impac==to no exterior, e que do mesmo modo são completamente independentes e jamais foram inscritos pelo célebre buril da história; assim como, por sua vez, são completamente independentes, em geral, do que acontece exteriormente. (SAUSSURE, $1^{\text {a }}$ C., 1891, f. 17, tradução nossa) ${ }^{10}$.

Nesse momento, Saussure parece desconsiderar sua própria afirmação (mostrada no trecho anterior) de que a história dos povos interfere, algumas vezes, na história da língua. Vemos que o linguista trata, no trecho acima, da diacronia, isto é, da história da língua. Nessa perspectiva, ele nega que as mudanças linguísticas ocasionem qualquer impacto no exterior de seu funcionamento e, por conseguinte, considera que elas não são inscritas na história dos povos e não sofrem qualquer influência dos fatos exteriores à língua. Essas considerações são questionáveis, visto que o acesso às mudanças linguísticas só pode ser feito por meio das produções culturais dos povos apreciadas ao longo do tempo.

10 No original: " C'est à l'autre point de vue par conseq ${ }^{c e}$ que la science du langage revendique le titre de science historique. C'est que tte langue a une histoire, en elle-même a une histoire qui se déroule perpé==tuellement, qui est faite d'une succession d'événements linguistiques, exemple quit lesquels n'ont point eu de reten==tissement au-dehors, de même qu'ils sont complètement indépendants et n'ont jamais été inscrits par le célèbre burin de l'histoire ; de même qu'à leur tour ils sont complètement indépendants en général de ce qui se passe au-dehors. ». 
O acesso à literatura permite conhecer as mudanças linguísticas e, a partir delas, chegar às leis que as regem. Isso possibilita, por consequência, conhecer o funcionamento do sistema linguístico e as propriedades desse sistema que ocasionam a mudança. Além disso, é preciso considerar que a história política - que compõe a história dos povos - bem como questões geográficas e questões culturais mais gerais incidem na língua, de forma a ocasionar modificações. Assim, destacamos que, por mais que Saussure procure separar a história da língua da história dos povos, parece haver, entre elas, uma íntima relação que impossibilita a distinção absoluta de ambas.

Acerca do trecho mencionado consideramos, ainda, que há outra interpretação possível. Compreendemos que a natureza histórica da ciência da linguagem está relacionada à sua independência do que ocorre no exterior, ou seja, dos fatos sociais em geral. Contudo, dada a sua relação com a história dos povos, a história da língua é dependente desses fatos para que exista, visto que ela só é possibilitada pelo registro linguístico de uma comunidade. Dessa forma, como pode o caráter histórico da língua ser reivindicado por um viés que desconsidera os elementos que a fazem existir?

Por ora, suspendemos essa questão, a fim de passarmos à análise da história nos documentos referentes aos cursos de Linguística Geral ministrados por Saussure.

\section{A história e os cursos de Linguística Geral}

A história ${ }^{11}$ aparece em alguns momentos das elaborações de Saussure sobre a língua apresentadas no CLG; entre eles, ressaltamos dois, que consistem em pontos cruciais da teorização do linguista: a abordagem diacrônica da língua e a delimitação dos elementos que compõem a Linguística externa. A respeito deste último, Saussure estabelece, no capítulo quinto da Introdução do CLG, que essa Linguística que lida com os elementos de caráter externo se ocupa "de coisas importantes", as quais incidem diretamente no estudo da linguagem (cf. SAUSSURE, 2006 [1916], p. 29). A história e os costumes da sociedade estão entre os elementos que são exteriores ao sistema linguístico, mas cuja relevância é elucidada pelo linguista. Segundo ele:

Incluem elas [as coisas importantes], primeiramente, todos os pontos em que a Linguística confina com a Etnologia, todas as relações que podem existir entre a história duma língua e duma raça ou civilização. Essas duas histórias se associam e mantêm relações recíprocas. Isso faz recordar um pouco as correspondências verificadas entre os fenômenos linguísticos propriamente

11 Embora, em alguns momentos, seja possível estabelecer uma aproximação entre a noção de história, em Saussure, e conceito de história estabelecido pelo filósofo romano M. T. Varrão, não nos ateremos a tratar explicitamente dessa aproximação, tendo em vista que ela extrapola os limites deste artigo. 
ditos. Os costumes duma nação têm repercussão na língua e, por outro lado, é em grande parte a língua que constitui a Nação. (SAUSSURE, 2006 [1916], p. 29, grifo nosso).

Tal como já afirmamos é por meio da língua que a história de um povo é construída e registrada; fora da sociedade, uma língua cessa de existir, pois deixa de haver falantes que possam continuá-la. Em contrapartida, a trajetória de uma sociedade incide diretamente na língua de seu povo, ocasionando modificações lexicais, fonéticas e de outras ordens. Há, dessa forma, uma via de mão dupla.

A respeito da influência da história da sociedade e dos povos em uma língua particular, Saussure destaca, nomeadamente, a questão da história política. Trata-se do segundo elemento determinado pelo linguista como componente da Linguística externa:

Em segundo lugar, cumpre mencionar as relações existentes entre a língua e a história política. Grandes acontecimentos históricos, como a conquista romana, tiveram importância incalculável no tocante a inúmeros fatos linguísticos. A colonização, que não é senão uma forma de conquista, transporta um idioma para meios diferentes, o que acarreta transformações nesse idioma. (SAUSSURE, 2006 [1916], p. 29, grifo nosso).

Vemos que a língua que é falada em uma sociedade não está completa e acabada; ela não é imune às interferências e influências de outras línguas e de outras culturas ocasionadas por eventos histórico-políticos. Por isso, Saussure defende que esses elementos não devem ser desconsiderados na análise das línguas, muito embora os coloque no patamar de elementos externos ao sistema linguístico.

É claro que há um grande engajamento de Saussure em busca de separar esses elementos e fenômenos sociais da Linguística que propõe. Contudo, não acreditamos que seja possível cumprir essa tarefa com sucesso em todo o percurso de delimitação da língua. Como temos mostrado, a todo instante, os fenômenos sociais incidem na delimitação saussuriana de um objeto formal para a Linguística de caráter interno; isto é, a própria teorização do linguista, embora busque desvincular os fenômenos sociais do sistema de língua, frequentemente recorre a eles para que consiga defini-lo.

Como dissemos, a história também compõe as elaborações de Saussure sobre a língua, na distinção estabelecida por ele entre diacrônico e sincrônico. O linguista afırma que "de modo geral, é muito mais fácil fazer a Linguística estática [sincrônica] que a histórica [diacrônica]" (SAUSSURE, 2006 [1916], p. 117). A diacronia, por ser histórica, consiste no estudo da(s) língua(s) através do tempo. Por conseguinte, não há como abordar a história da língua sem considerar sua relação com este elemento. 
Assim, a história e o tempo se apresentam, no CLG, de forma relacionada às tradições linguísticas e aos costumes de determinado período. Isso pode ser notado no seguinte momento da edição:

Não basta, todavia, dizer que a língua é um produto de forças sociais para que se veja claramente que não é livre; a par de lembrar que constitui sempre herança de uma época precedente, deve-se acrescentar que essas forças sociais atuam em função do tempo. Se a língua tem caráter de fixidez, não é somente porque está ligada ao peso da coletividade, mas também porque está situada no tempo. (SAUSSURE, 2006 [1916], p. 88, grifo nosso).

Analisada com base em um curto período de tempo, a língua pode aparentar ser fixa e completa. Contudo, considerada através do tempo, percebe-se que ela está em constante mudança; essas mudanças, entretanto, só podem ser percebidas porque a língua, talvez paradoxalmente, continua, é "sempre herança da época precedente".

Vale ressaltar, ainda, a afirmação de Saussure de que a língua é "um produto das forças sociais"; essa é uma afırmação que compõe o segundo capítulo da primeira parte, intitulado "Princípios Gerais". Ela está presente, portanto, na parte da edição que é considerada por muitos como a responsável por apresentar a contribuição original de Saussure, ou seja, a busca pela definição de língua enquanto objeto formal e um sistema de signos. Entretanto, ela não parece ter sido considerada nas críticas dos estudiosos do século XX. A título de exemplo, podemos citar a denominação de "objetivismo abstrato", dada por Volochinov (1929), em Marxismo e Filosofia da Linguagem, em relação ao CLG. Segundo este autor, o sistema sincrônico não dá espaço para a enunciação e, desse modo, a interação verbal, que deve ser justamente o foco da linguística, fica desamparada se considerada no quadro teórico saussuriano (cf. FARACO, 2003).

Pensamos que esse tipo de afırmação baseia-se, principalmente, em uma leitura padrão do CLG, que considerou como ponto principal das elaborações saussurianas a concepção de língua enquanto sistema, desconsiderando, por outro lado, a definição de língua como instituição social e sua relação com os aspectos históricos, culturais e sociais de uma comunidade falante. Ademais, pode-se pensar também que a distinção metodológica entre língua e fala, efetuada por Saussure com o intuito de estabelecer um objeto de estudo para linguística, foi levada ao extremo, no sentido de que seus matizes não foram apreendidos.

Isso pode ser visto de maneira clara ao considerarmos as anotações de A. Riedlinger, referentes ao primeiro curso de linguística geral e que tocam na famosa distinção entre língua e fala: 
Dessas duas esferas, a esfera da fala é a mais social, a outra é a mais completamente individual. A língua é o reservatório individual; tudo o que entra na língua, ou seja, na cabeça, é individual. [...] Se tudo que é produzido de novo é criado na ocasião do discurso, isso quer dizer ao mesmo tempo que é do lado social da linguagem que tudo se passa. Em segundo lugar, é suficiente tomar a soma dos tesouros de língua individuais para se ter a língua. Com efeito, tudo isso que se considera na esfera interior do indivíduo é sempre social por que nada the penetra que <não seja > pela fala, primeiro <consagrado pelo uso > de todos na esfera da fala. (SAUSSURE apud RIEDLINGER, 1996, p. 65-66) ${ }^{12}$.

A princípio, o excerto acima pode ser considerado contrário àquilo que está explicitado no CLG, tendo em vista que na edição a língua é tomada como social e a fala como individual. Para nós, o que é colocado em questão é justamente a interação verbal e seu papel na transmissão e mudança da língua: a esfera da fala é mais social, pois é por meio dela que o falante se comunica, na ocasião do discurso, ou seja, inseridos em um determinado contexto histórico-social.

Se a fala é considerada social é justamente porque está inserida em uma determinada situação de comunicação que demanda ao falante não só a mobilização da língua como também a adequação às necessidades do discurso. (cf. SAUSSURE apud RIEDLINGER, 1996, p. 65). Percebe-se, desse modo, que a distinção entre língua e fala é metodológica, no sentido de que essas duas esferas estão tão imbricadas uma na outra que, muitas vezes, se determinam.

Mas, e a história? Em que aspecto ela pode ser pertencente a uma concepção de língua como instituição social, considerando, principalmente, sua relação com a fala? No próximo tópico, discorreremos um pouco acerca dos manuscritos saussurianos das lendas germânicas com o objetivo de iluminar a relação estabelecida entre língua, fala e história.

12 No original: "Des ces deux sphères la sphère parole est la plus sociale, l'autre est la plus complètement individuelle. La langue est le réservoir individuel; tout ce qui entre dans la langue, c'est-à-dire dans la tête, est individuel. [...] Si tout ce qui se produit de nouveau s'est créé à l'occasion du discours c'est dire que en même temps que c'est du côté social du langage que tout ce passe. D'autre <part> il suffira de prendre la somme des trésors de langue individuels pour avoir la langue. Tout ce que l'on considère en effet dans la sphère intérieure de l'individu est toujours social parce que rien n'y a pénétrer qui <ne soit> d'abord <consacré par l'usage> de tous dans la sphère extérieure de la parole. ». 


\title{
3 A história e os Niebelungen
}

No que diz respeito à relação entre língua e história dos povos nos manuscritos sobre as lendas germânicas, temos como ponto de partida o fato de que a história dos povos já se encontra na própria motivação do linguista ao se debruçar sobre estas narrativas. Além de podermos rememorar a famosa carta enviada a Meillet em 1906, na qual Saussure evidencia seu "prazer histórico", temos que os aspectos ligados à história dos povos foram levados a público pelo linguista em suas participações nas sessões da Société d'Histoire et Archéologie de Genève. Em uma delas, ministrada em 1904 e intitulada Les burgondes et la langue burgonde en pays romaine, Saussure (1922 [1904], p. 606, tradução nossa ${ }^{13}$ ) explicita que:

\begin{abstract}
Assentados primeiro na bacia do Elba, depois no Wurtemberg atual, os burgúndios, antes de se fixarem em nossas terras, formaram no médio Reno, em torno de Worms, um Estado efêmero, cuja lembrança, embelezada pela poesia, transmitiu-se de geração em geração nas narrativas e canções épicas referentes aos Niebelungen.
\end{abstract}

Dessa afirmação decorre que há a possibilidade de se retomar, pela análise das narrativas lendárias, não só a língua burgúndia, como também os vestígios da história de seu povo. Além disso, deve-se ressaltar que as narrativas e canções épicas às quais o linguista se refere foram transmitidas oralmente durante séculos: estima-se que o Niebelungen, por exemplo, se refira a acontecimentos históricos ocorridos em 435 a.C, tendo sido transcritos somente em 1200 d.C. Obviamente, a natureza da literatura oral está ligada à fala e, consequentemente, à língua e às mudanças linguísticas. Temos, nesse sentido, uma confluência de interesses e a assunção de que língua e história estão em constante relação.

Com o intuito de ilustrarmos o alcance teórico dessa pesquisa, selecionamos alguns trechos em que Saussure discorre sobre a história do povo burgúndio, da qual teria se originado a lenda dos Niebelungen:

Que extraordinário tesouro para a história não teríamos nos Nibelungenlied? Toda a vida do pequeno reino burgúndio de $435, . .$. ] estaria lá sob nossos olhos, e com uma profusão de detalhes incomparável. Um furo da história seria substituído por uma fonte abundante, o que nos desperta desconfiança e nos leva a dizer que; ou toda essa lenda é um produto de invenção, o que é improvável, ou se

13 No original: «Établis d'abord dans le bassin de l'Elbe, puis dans le Wurtemberg actuel, les Burgondes, avant de se fixer dans nos contrées, avaient formé sur le Rhin moyen, autour de Worms, un État éphémère, dont le souvenir, embelli par la poésie, s'est transmis de génération en génération dans les récits et les chansons épiques relatifs aux Nibelungen. ». 
ela é executada sob um fundo histórico, todas as chances são para que ela seja executada sob um fundo histórico absolutamente conhecido e retomado pelos cronistas paralelamente ao que ela oferece a ela mesma. (SAUSSURE/LEG, 1986, p. 21, tradução nossa) $)^{14}$.

Na citação acima, o linguista não afirma apenas o fundo histórico dessa lenda, como também a existência de algo paralelo que ela oferece por si mesma. Ao que nos parece, há aqui a constatação de que a lenda, sendo uma narrativa oral, possui um funcionamento próprio: enquanto contada e recontada pelos poetas, ela não seria estática. Ora, é importante lembrar que o ato de contar uma lenda tinha um caráter convencional, tendo em vista que era uma prática social de determinadas culturas, utilizada para transmitir a história dos povos em uma época em que a escrita era privilégio de poucas pessoas. Temos, dessa forma, a consideração, por parte de Saussure, da situação de comunicação e da função social desempenhada pelo poeta, ou seja, das necessidades do discurso. Isso fica evidente no seguinte trecho, em que Saussure discorre sobre o papel da falta de memória na transmissão das narrativas orais:

A falta de memória desempenha um papel pela parte dos detentores encarregados da lenda é um elemento <psicológieo> negativo que, em tal matéria, é forȩado a produzir um resultado <consideravelmente> positivo: a invenȩão de qualquer eoisa para substituirisso que não vem à memória no momento desejado.

\section{Não há uma avó contando uma história aos seus netos que, quando I}

Falta de memória. A invenção de qualquer coisa para substituir <outra coisa> que não vem à memória < do contador> no momento desejado é para o contador uma pequena humilhação passageira que ele tenta dissimular <de seu público>, e para o destino geral da lenda, é um dos maiores e mais regulares fatores de transformação. Podemos dizer que o esquecimento age aqui como um fator <psicológico> positivo (porque é necessário a todo preço reparar o esquecimento), e <é necessário acrescentar que nós vemos o mesmo fenômeno no domínio infinitamente mais delicado das formas linguísticas.>. (SAUSSURE/LEG, 1986, p. 440 , tradução nossa) $)^{15}$.

14 No original: "Quel extraordinaire trésor pour l'histoire n'aurions-nous pas alors dans le Nibelungenlied? Toute la vie du petit royaume burgonde de 435, autrement à peine certifié dans son existence par deux mentions de Chroniques, serait là sous nos yeux, et avec une profusion de détails incomparable! Un trou de l'histoire serait remplacé par une abondante <source>. Voilà qui éveille quelque défiance, et qui amène au moins à se dire ceci; ou bien toute cette copieuse légende est un pur produit d'invention, ce qui est improbable, ou bien si elle court sur un fond historique toutes chances sont pour qu'elle coure sur un fond historique absolument connu et recuilli par des chroniqu<eurs>, parallèlement à ce qu'elle offre elle-même. ».

15 No original: «Le manque de mémoire de la part des détenteurs attitrés de la légende est 
Na citação acima podemos depreender que o narrador, enquanto responsável pela transmissão dos fatos históricos, possui determinados critérios a seguir no momento da recitação. De fato, o indivíduo interessado em seguir essa função passava por todo um treinamento, que contemplava tanto a memorização da narrativa quanto questões de entonação, adequação ao público e mecanismos de acréscimo/substituição nos momentos em que a memória Ihe faltasse (cf. BÃUML; SPEILMAN, 1975). O poeta possui, desse modo, uma liberdade regrada no momento de narrar uma lenda, o que implica, inclusive, um tipo de autoria específico, como aponta Hermann (1999), de acordo com a qual a autoria nas narrativas orais ocorre no momento em que elas são contadas, fazendo com que o poeta ocupe, ao mesmo tempo, a função de ator e criador.

Nesse sentido, temos que a memória age na narrativa da mesma maneira com que age na língua, o que implica o mecanismo linguístico, ou seja, a mobilização da língua pelo falante por meio dos eixos associativos e sintagmáticos. No que concerne à relação entre lenda e história, temos que os fatos históricos estão submetidos, concomitantemente, à memória e ao funcionamento da língua.

Ainda na citação acima, tem-se que Saussure titubeia entre considerar a ausência de memória enquanto um fator negativo ou enquanto um fator positivo. Ao que nos parece, ele acaba por se decidir pela positividade dessa ausência, tendo em vista que é ela a responsável pela inserção de "qualquer coisa" que substitua uma lacuna na narrativa, ocasionando, assim, as mudanças na lenda.

O funcionamento específico da narrativa oral, que se ancora no funcionamento linguístico, não impede que lenda seja um veículo de transmissão da história, entretanto, os acontecimentos históricos não são transmitidos de maneira uniforme e estática. Considerando esse funcionamento que é próprio da lenda, faz-se necessário a Saussure considerar, em suas elaborações, as relações e mudanças que podem ocorrer na narrativa. Assim, percebe-se nos manuscritos um grande esforço para se enxergar pontos comuns entre a história do povo burgúndio e o enredo do Niebelungen: o linguista realiza um levantamento dos dados históricos, que já apresentam incompatibilidades quando se comparam documentos distintos e, depois, compara esses dados com aquilo que se encontra na lenda. Vejamos um exemplo dessa comparação:

un élément <psychologique> négatif, qui, en telle matière, est forcé de produire un résultat <considérablement> positif: I'invention de quelque chose pour remplacer ce qui ne revient pas à ta mémoire au moment voulu. II n'y a pas une grand maman racontant une histoire à ses petits enfants qui, lorsque [ "Manque de mémoire. L'invention de quelquer chose pour remplacer <une autre chose> qui ne revient pas à la mémoire < du conteur> au moment voulu, est pour le conteur une petite humiliation passagère qu'il essaie de dissimuler <à son public>, pour la destinée générale de la légende un des plus énormes <et de plus régulièrs > facteirs de transformation. On peut dire que l'oubli agit ici comme une facteur <psychologique> positif (parce qu'il faut a tout prix réparer l'oubli), et <il faut> ajouter nous assistons exactêment au même phénomène dans le domaine infiniment plus délicat des formes linguistique ». 
[...]- A irmã de Brynhildr, Volsunga Saga capítulo XXIII chama-se Bekkhildr, mas tem um filho Alsvidr cujo nome lembra Galesvinthe.

- (De resto, Bekkhildr é esposa de um simples hofdingi, que é o título de Heimir.) -

$<$ Cremou-se (por marca de infâmia) o corpo de Brunehaut. Cf; a fogueira de Brünhilde - ver Hist. França, p. 272 ata de abertura do testamente de Brunehaut>

- Brynhildr parece não ter nascimento real, como Frédégonde, mas se nos ativermos a esse ponto, é necessário rasurar o item precedente que supõe precisamente Brynhildr = Brunehaut.

- O casamento de Brunehaut com o sobrinho de seu marido (que deu lugar ao concílio) pode lembrar a discussão Sigfried-Gunther sobre Brünhilt de quem ambos eram maridos. (SAUSSURE,/LEG, 1896, p. 50-51, tradução nossa) ${ }^{16}$.

Esse trecho pertence a uma folha cujo título é "Coincidências entre a história de Fredégonde e Brumhild". A folha subsequente, por sua vez, possui o título de Nãocoincidências. Uma dificuldade adicional encontrada pelo linguista em suas análises foi a de que, por ser de natureza oral e, desse modo, ter sido transmitida em territórios distintos por poetas diferentes - com seus respectivos repertórios e ausências de memória -, a lenda dos Niebelungen possui mais de uma versão. Desse modo, Saussure tinha que, além de comparar os dados históricos com o enredo da narrativa, comparar as várias versões das narrativas entre si, as quais podiam diferir tanto em relação à época, quanto em relação ao território em que foram contadas.

É possível pensar, nesse sentido, que há, da mesma forma que no âmbito da linguística, uma distinção entre a história dos povos e a história da lenda, isto é, entre a história humana e a diacronia lendária. E isso porque é perceptível, durante todo o conjunto de manuscritos saussurianos sobre a lenda, um interesse duplo relacionado à história: primeiro, pela história dos povos antigos, principalmente do povo burgúndio, do qual havia poucos registros; e, segundo, pela diacronia da lenda no sentido de apreender o mecanismo ao qual os fatos históricos estão submetidos a partir do momento em que se tornam narrativas orais (cf. HENRIQUES, 2019).

16 No original: « [...] - La soeur de Brynhildr, Volsunga Saga chap. XXIII, s'appele Bekkhildr, mais ele a um fils Alsvior dont le nom rappelle Galesvinthe. - (Du reste est femme d'un simple hofdingi qui est le titre de Heimir.) - Brynhildr, paraît de naissance non royale comme Frédégonde, mais si l'on s'attache à cela il faut biffer l'article précédent qui suppose précisement Brynhildr = Brunehaut. - Le mariage de Brunehaut avec neveu de son mari (qui donna lieu à concile) peut rappeler la discussion de Sigfried-Gunther à propos de Brünhilt dont ils étaient tous 2 époux. ». 


\section{Considerações finais}

Neste artigo, tivemos o objetivo de demonstrar que é possível apreender relações entre história e língua, nas elaborações de Saussure, a partir do momento em que consideramos que a língua não pode ser concebida, no arcabouço teórico saussuriano, somente enquanto um sistema de signos arbitrários que possui uma ordem própria independente de qualquer ordem que Ihe seja exterior. Na verdade, ela deve ser considerada, antes de mais nada, como uma instituição social tão imbricada na sociedade que não é possível conceber uma sem a outra.

Nesse sentido, apesar de ser uma necessidade metodológica, no início do século XX, estabelecer um objeto de estudo nos moldes de uma ciência positivista, a relação íntima entre língua e sociedade e, consequentemente, a história, se faz presente a todo momento nas elaborações saussurianas. Na P.C, como vimos, Saussure tenta estabelecer uma distinção entre a história da língua e a língua na história, entretanto, ao mesmo tempo que essa distinção é desejada pelo linguista, ela não parece se deixar estabelecer. No CLG, os aspectos histórico-sociais incidem, a todo instante, na definição de língua enquanto sistema de signos, inclusive no que concerne à própria distinção entre língua e fala, o que indica justamente a potencialidade de considerar a língua, antes de tudo, enquanto uma instituição social, definição que parece ter passado desapercebida pelos leitores da edição no século XX.

Por fim, nos manuscritos saussurianos sobre as lendas germânicas, vemos a confluência da história dos povos e da diacronia da lenda, que estão submetidos ao funcionamento da língua, não só entendida enquanto sistema - tendo em vista as relações associativas e sintagmáticas -, como também enquanto instituição social, sendo considerada em seu uso em uma determinada situação comunicativa.

\section{REFERÊNCIAS}

BÃUML, F.; SPEILMAN, E. From Illiteracy to literacy: prolegomena to a study of the Nibelungenlied. In: BÃUML, F.; SPEILMAN, E. Oral Literature. W. C. Henderson \& Son: Britain, 1975.

CHIDICHIMO, A. Les premières leçons de Saussure a Genève, 1891: textes, temoins, manuscrits. Cahiers Ferdinand de Saussure. Revue suisse de linguistique générale. Genève: Librairie Droz S.A, n. 62. p. 257-277. Publicado por Cercle Ferdinand de Saussure, 2009.

CHOMSKY, N. Aspects of the theory of syntax. Cambridge: The M.I.T. Press, 1965. 
CHOMSKY, N. Novos Horizontes no Estudo da Linguagem. DELTA [online], v. 13, p. 5174, 1997. Disponível em: http://www.scielo.br/scielo.php?script=sci_arttext\&pid=S0102$44501997000300002 \&$ lng=en\&nrm=iso. Acesso em: 18 set. 2018.

DURKHEIM, E. Fato social e divisão do trabalho. Comentário de R. Musse. São Paulo: Editora Ática, 2011 [1893].

FARACO, C. A. Linguagem e diálogo: as ideias linguísticas do círculo linguístico de Bakhtin. Curitiba: Criar Edições, 2003.

HENRIQUES, S. M. Os manuscritos de Ferdinand de Saussure sobre as lendas germânicas: uma relação entre a fala e a história. 2019. Tese (Doutorado em Linguística) - Instituto de Estudos da Linguagem, Universidade Estadual de Campinas, Campinas, 2019.

HERMANN, N. The Development of the Nibelungen-legend in Various Periods of German Literature. 1991. Dissertation (Master) - Dalhousi University, Halifax, Nova Scotia, 1999.

LABOV, W. Sociolinguistique. Tradução A. Khim. Paris: Les Édition de Minuit, 1976 [1972].

MEILLET, A. Linguistique Historique et Linguistique Générale. Paris: Librairie Honoré Champion, 1958 [1921].

MEILLET, A. Développements linguistiques. Linguistique Historique et Linguistique Générale. Paris: Librairie Honoré Champion, 1958 [1918].

SAUSSURE, F. Curso de linguística geral. Tradução A. Chelini; J. P. Paes e I. Blikstein. 27. ed. São Paulo: Cultrix, 2006. Cours de linguistique general. Charles Bally e Albert Sechehaye (org.), com a colaboração de Albert Riedlinger, [1916].

SAUSSURE, F. Deuxième Cours de Linguistique Générale (1908-1909): d'après les cahiers d'Albert Riedlinger et Charles Patois/ Saussure's second course of lectures on general linguistics (1910-1911): from the notebooks of Albert Riedlinger and Charles Patois. French text edited by Eisuke Komatsu e English text edited by George Wolf. Pergamon Press, 1997.

SAUSSURE, F. Première Cours de Linguistique Générale (1907): d'après les cahiers d'Albert Riedlinger / Saussure's first course of lectures on general linguistics (1907): from the notebooks of Albert Riedlinger. French text edited by Eisuke Komatsu e English text edited by George Wolf. Pergamon Press, 1996. 
SAUSSURE, F. Troisième Cours de Linguistique Générale (1910-1917): d'après les cahiers d'Emile Constantin / Saussure's third course of lectures on general linguistics (19101911): from the notebooks of Emile Constantin. French text edited by Eisuke Komatsu e English text edited by Roy Harris. Pergamon Press, 1993.

SAUSSURE, F. Le Leggende Germaniche. Scritti scelti e annotati a cura di Anna Marinetti e Marcello Meli, Zielo, Este, 1986.

SAUSSURE, F. Cours de Linguistique Générale. Édition critique par Rudolf Engler (Tome 1).Wiesbaden: Harrassowitz, 1968.

SAUSSURE, F. Cours de Linguistique Générale. Édition critique preparé par Tulio de Mauro. Paris: Payot, 1967.

SAUSSURE, F. Recueil des publications scientifiques de Ferdinand de Saussure. Texte établi par Charles Bally e Léopold Gautier. Payot/Droz: Géneve, 1922 (p. np-631).

SAUSSURE, F. Première conférence à l'Université (cours d'ouverture, novembre 1891). In: Papiers Ferdinand de Saussure, 3951/1. Bibliotèque de Genève, 1891.

SILVEIRA, E. M. As marcas do movimento se Saussure na fundação da Linguística. Campinas: Mercado de Letras, 2007.

SECHEHAYE, A. C. Phonétique du grec et du latin: cours de M. Ferdinand de Saussure - Université de Genève 1891-1892. Texte établi par Alessandro Chidichimo. Cahiers Ferdinand de Saussure. Revue suisse de linguistique générale. Genève: Librairie Droz S.A, n. 62. p. 279-288. Publicado por Cercle Ferdinand de Saussure, 2009.

TESTENOIRE, P. Y. A sombra do Curso (1960-1980). Revista Leitura: Novo retorno a Saussure, Maceió, v. 1, n. 62, p. 394-414, 2019.

VOLOCHINOV, V. N. Marxismo e Filosofia da Linguagem. Problemas fundamentais do Método Sociológico na Ciência da Linguagem. Tradução Michel Lahud e Yara Frateschi Vieira com a colaboração de Lúcia Teixeira Wisnik e Carlos Henrique D. Chagas Cruz. São Paulo: Editora Hucitec, 1979 [1929]. . 